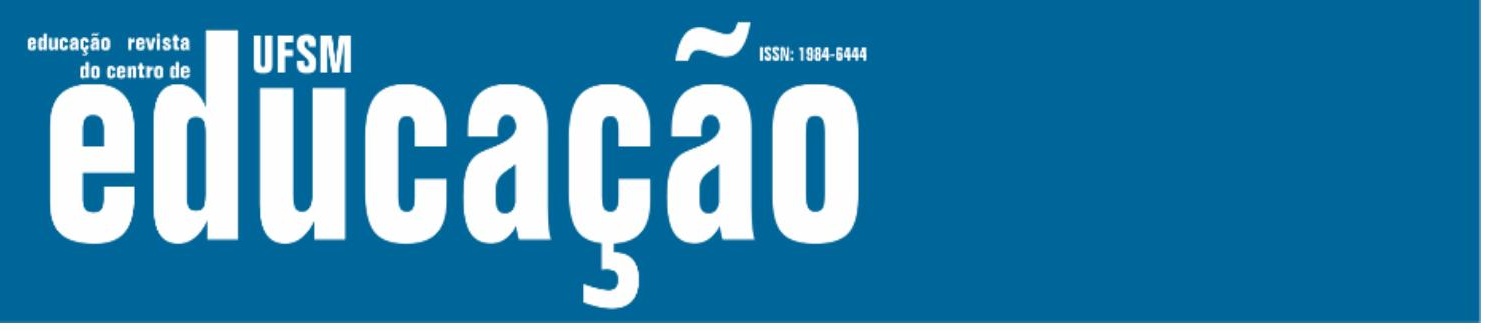

ISSN: 1984-6444 | http://dx.doi.org/10.5902/1984644439187

\title{
A sustentabilidade e o Desenvolvimento do Programa Dinheiro Direto na Escola- Escolas Sustentáveis, em Aracaju, Sergipe
}

\section{Sustainability and the Development of the Direct Money Program in School - Sustainable Schools, Aracaju, Sergipe}

Maraisa de Oliveira Silva

Egressa do Programa de Pós-Graduação da Universidade Tiradentes, Aracaju, Sergipe, Brasil. mara.oliveira20@hotmail.com - https://orcid.org/0000-0002-9591-6630

Joyce Kelly Fabiano Passos

Discente na Universidade Tiradentes, Aracaju, Sergipe, Brasil.

kellyfabianops@outlook.com - https://orcid.org/0000-0002-6576-7515

Daniela Oliveira Carvalho

Discente na Universidade Tiradentes, Aracaju, Sergipe, Brasil.

kellyfabianops@outlook.com - https://orcid.org/0000-0002-6576-7515

Cristiane Costa da Cunha Oliveira

Professora Doutora na Universidade Tiradentes, Aracaju, Sergipe, Brasil.

criscunhaoliva@yahoo.com.br - https://orcid.org/0000-0003-1439-7961

\section{Andressa Sales Coelho}

Professora Doutora na Universidade Tiradentes, Aracaju, Sergipe, Brasil. andscoelho@yahoo.com.br - https://orcid.org/0000-0001-9042-682X

Recebido em 23 de janeiro de 2020

Aprovado em 19 de fevereiro de 2020

Publicado em 18 de novembro de 2020

\section{RESUMO}

O Programa Dinheiro Direto na Escola-Escolas Sustentáveis (PDDE-ES), financia projetos em escolas públicas com o objetivo de transformar o ambiente escolar em espaços educadores sustentáveis. A pesquisa teve como objetivo descrever o desenvolvimento do PDDE-ES em escolas públicas de Aracaju, Sergipe, quanto aos aspectos de educação ambiental, sustentabilidade e Projeto Político Pedagógico (PPP). O método utilizado foi aplicação de questionários aos gestores e professores de doze escolas participantes. Foram realizadas análises de frequência e análises bivariadas das variáveis (1) conhecimento dos objetivos e (2) dificuldades encontradas na aplicação de práticas sustentáveis com variáveis sóciodemográficas e profissiográficas. Os resultados mostraram que $83,3 \%$ das escolas inscritas no programa ainda não haviam recebido o recurso. Sobre os objetivos propostos pelo programa, $83,3 \%$ dos gestores conheciam os objetivos, mas a maioria dos 


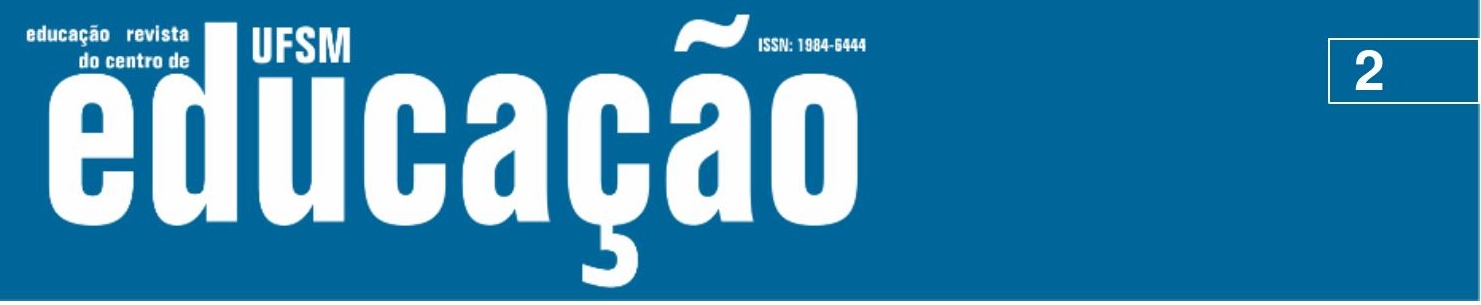

ISSN: 1984-6444 | http://dx.doi.org/10.5902/1984644439187

professores $(61,2 \%)$ desconhecia e não participou da construção do plano de ação. Gestores e professores ressaltaram dificuldades na execução de práticas de Educação Ambiental e sustentabilidade, mostrando fragilidade na comunicação entre gestão e corpo docente, que aliada à falta de recurso financeiro e de planejamento, não contribuem para a efetiva realização das atividades e concretização do programa. Conclui-se que as fragilidades apontadas reforçam a necessidade da inserção de temas ambientais no PPP da escola além de capacitação e formação continuada para esses profissionais atuarem de forma mais efetiva. O PDDE-ES é de suma importância para que as escolas trabalhem as questões socioambientais estimulando a mudança de hábitos e ações da comunidade na busca por alternativas mais sustentáveis e conservação ambiental local.

Palavras-chave: Escola, Educação Ambiental, Sustentabilidade.

\section{ABSTRACT}

The Direct Money in School - Sustainable Schools Program (PDDE-ES) finances projects in public schools with the goal of transforming the school environment into sustainable educational spaces. The research aimed to describe the development of the PDDE-ES in public schools in Aracaju, Sergipe, regarding environmental education, sustainability and the Political Educational Project (PPP). The process worn was an application of questionnaires to the managers and teachers of the twelve participating schools. Frequency analyzes and bivariate analyzes of the variables (1) knowledge of the objectives and (2) difficulties encountered in the application of sustainable practices with socio-demographic and professional variables were performed. The results showed that $83.3 \%$ of the schools enrolled in the program had not yet received the resource. Regarding the objectives proposed by the program, $83.3 \%$ of the managers knew the objectives, but most of the teachers $(61.2 \%)$ were unaware of and did not participate in the construction of the action plan. Managers and teachers highlighted difficulties in the implementation of Environmental Education and Sustainability practices, revealing fragility in the communication between management and faculty, which along with the lack of financial resources and planning, do not contribute to the effective accomplishment of the activities and implementation of the program. We concluded that the weaknesses pointed out reinforce the need for the insertion of environmental themes in the PPP of the schools, besides training and continuous training so that these professionals can act more effectively. The PDDEES is of utmost importance for schools to work on social and environmental issues by encouraging changes in community habits and actions in the search for more sustainable alternatives and local environmental conservation.

Keywords: School, Environmental Education, Sustainability. 


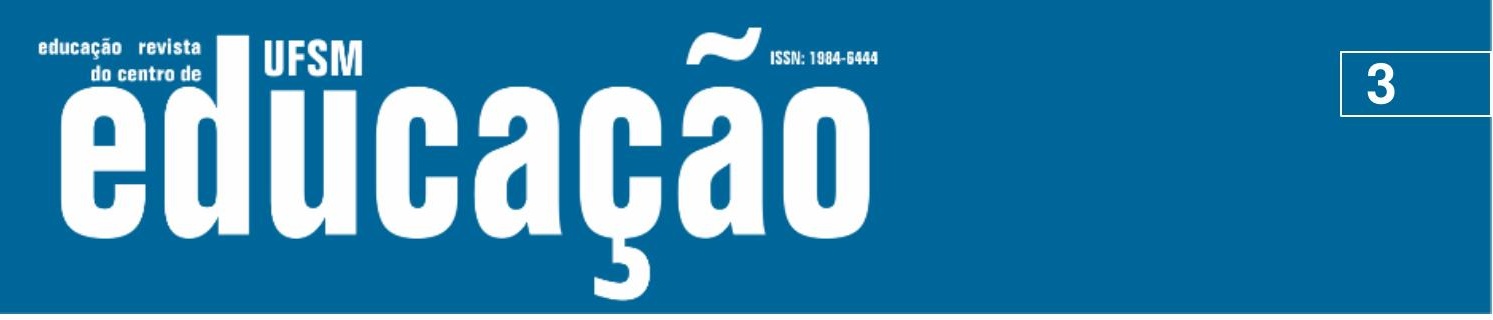

ISSN: 1984-6444 | http://dx.doi.org/10.5902/1984644439187

\section{Introdução}

A escola é um ambiente que favorece a construção do conhecimento e pode se tornar um espaço educador sustentável por meio da inserção de questões socioambientais focando na adequação do espaço físico, gestão e currículo e no envolvimento de toda a comunidade escolar e seu entorno na busca por propostas que contemplem as necessidades locais (DOURADO et al., 2015; SÁ, et al., 2015).

Quando escolas trabalham a mudança para espaços educadores sustentáveis e articulam junto ao currículo a temática ambiental, realizando práticas sustentáveis no seu cotidiano, o aluno tem a oportunidade de desenvolver habilidades e mudar seus hábitos com relação ao meio ambiente, uma vez que, essas ações contribuem para o conhecimento e formação de um cidadão preocupado com suas atitudes dentro do ambiente onde está inserido (MIGUEIS, 2014).

A proposta de mudança no ambiente escolar para um contexto sustentável vêm constantemente sendo apoiada e incentivada pelos Governo Federal, Ministério da Educação e Cultura (MEC) e o Instituto Nacional de Estudos e Pesquisas Educacionais Anísio Teixeira (Inep), um exemplo, foi a pesquisa realizada pelo Inep sobre a Educação Ambiental realizada nas escolas do ensino fundamental, essa pesquisa foi feita a partir dos dados do Censo Escolar, o estudo teve como objetivo fazer um levantamento e obter um panorama das escolas que trabalhavam as questões ambientais em topo o país (BRASIL, 2007a). A Associação Nacional de PósGraduação em Educação (Anped) analisou entre 2001 e 2004, por meio do Censo Escolar, as escolas brasileiras que trabalharam a Educação Ambiental e encontrou que em 2001, 61,2\% das escolas (115 mil) inseriram essa temática e em 2004 esse número subiu para 94\%, representando 152 mil escolas (BRASIL, 2007a).

Em 2012, foi publicado pelo MEC junto com algumas Secretarias o livreto "Vamos Cuidar do Brasil com Escolas Sustentáveis", cujo conteúdo incentivava a inserção da Educação Ambiental e questões ambientais, sociais e culturais no dia-adia escolar, educando seus alunos para a sustentabilidade ambiental e para adequação do seu espaço com a proposta de escolas sustentáveis (BRASIL, 2012). 


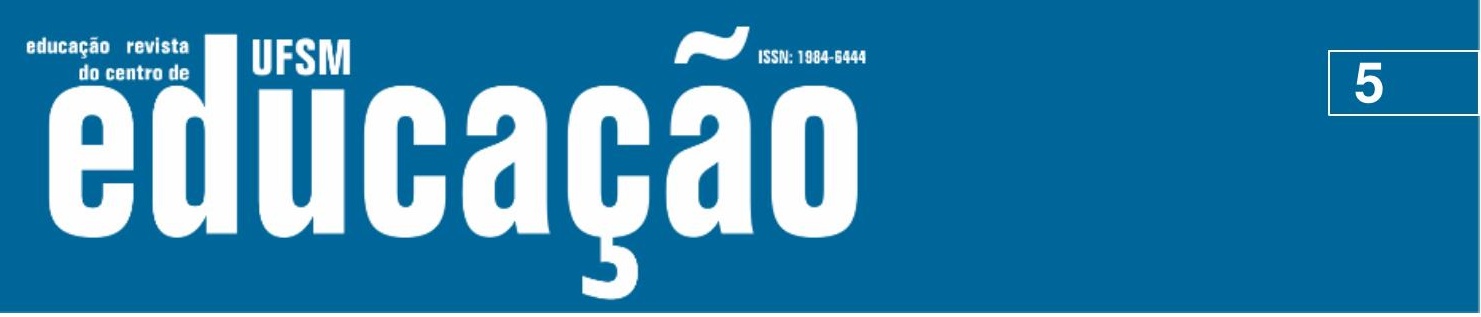

ISSN: 1984-6444 | http://dx.doi.org/10.5902/1984644439187

Conferência das Nações Unidas sobre Meio Ambiente e Desenvolvimento (ECO92), realizada no Rio de Janeiro em 1992. A metodologia, chamada de Oficina de Futuro, permite que os alunos, professores, pais e comunidade façam parte de todo o planejamento escolar construindo projetos coletivamente com o propósito de mostrar que para alcançar a sustentabilidade é essencial o envolvimento de todos (BRASIL 2004).

A metodologia Oficina do Futuro apresenta etapas para delineamento e desenvolvimento de projetos de acordo com o objetivo e planejamento proposto pelo grupo. Todas as etapas são conduzidas por meio de perguntas pré-estabelecidas que devem ser respondidas pelos participantes para alcançar o objetivo da etapa. A proposta inicia com a "Árvore dos Sonhos" onde os participantes constroem uma árvore e respondem a questões relacionadas aos seus desejos ou sonhos para a escola e/ou comunidade e posteriormente, definem aqueles prioritários que se tornam o objetivo do grupo. Na etapa "Pedras no Caminho" são discutidas as e desafios para alcançar o objetivo/sonho e organizados em ordem de prioridade para serem solucionados.-O terceiro passo da metodologia consiste em criar um Jornal Mural: “Viagem ao Passado e ao Presente”, onde são colhidas informações sobre a história da escola/comunidade permitindo organizar sua memória e conhecer seu processo de construção, crescimento e desenvolvimento até a atualidade nos âmbitos social, ambiental, econômica e cultural.

Os próximos passos são a "Com-Vida para a ação" e envolvem o planejamento e organização das atividades e um plano de ação com atores definidos cujo intuito é concretizar os sonhos propostos. O monitoramento das ações é importante para avaliar o andamento e sucesso do processo, onde o grupo identificará se conseguiu resolver seus problemas e se estes causaram os impactos desejados. Além do acompanhamento das ações, as parcerias dentro e fora da escola são essências, para que, a Agenda 21 na escola consiga alcançar os resultados previstos no projeto (BRASIL, 2007b). A proposta da Com-Vida serve para mostrar a importância do meio ambiente e da responsabilidade de cada cidadão em mantê-lo conservado e de forma efetiva vem contribuindo para que a Educação Ambiental e a Sustentabilidade estejam inseridas na escola/comunidade (BRASIL, 2012). 


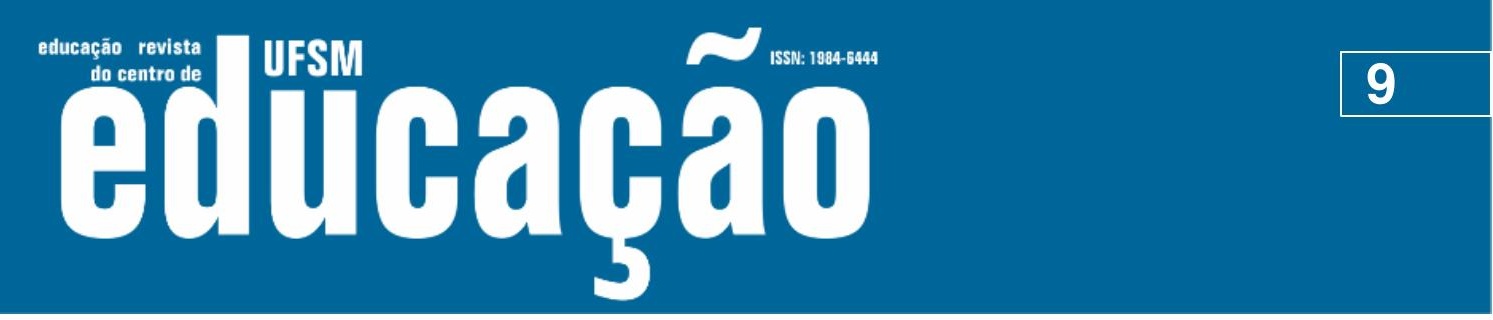

ISSN: 1984-6444 | http://dx.doi.org/10.5902/1984644439187

as variáveis sócio-demográficas e profissiográficas (sexo, faixa etária, nível de escolaridade e tempo de gestão, tempo de magistério).

A pesquisa foi submetida e aprovada pelo Comitê de Ética em Pesquisa da Universidade Tiradentes, sob o Parecer $\mathrm{n}$ ํ 1.872.752, em 17 de dezembro de 2016.

O texto foi organizado em Introdução, incluindo os métodos. Resultados e discussão, esse subdividido em: Perfil de gestores e professores; Programa Dinheiro Direto na Escola; Dificuldades na execução de atividades e projetos de Educação Ambiental; Interferência do PDDE-ES na comunidade; Projeto Político Pedagógico. E também a Conclusão.

\section{Resultados e discussão}

\section{Perfil de Gestores e professores}

Os gestores eram em maioria (75\%) do sexo masculino, com idade média de 44 anos e 66,7\% estavam na gestão da escola por um período de sete meses a dois anos. Quanto à formação acadêmica 33,3\% dos gestores tinha curso superior em geografia e $25 \%$ em pedagogia, 58,3\% possuía curso de especialização.

Quanto aos professores, 81,6\% eram do sexo feminino, a faixa etária média foi de 39 anos, 56,3\% tinham formação em pedagogia, 68\% possuíam especialização e $75,7 \%$ lecionava do $1^{\circ}$ ao $5^{\circ}$ ano. O tempo de magistério foi semelhante para as categorias até 12 anos de magistério (48,5\%) e mais de 12 anos $(41,7 \%)$.

\section{Programa Dinheiro Direto na Escola}

Quanto ao recebimento do recurso do Programa Dinheiro Direto na Escola Escolas Sustentáveis (PDDE-ES), apenas duas (16,7\%) das 12 escolas inscritas no programa em 2014, receberam a verba no início do ano de 2017 . O atraso ou não recebimento do recurso por essas escolas contempladas no programa após três anos de inscrição é um ponto que precisa ser discutido, uma vez que, como traz o manual do Programa Dinheiro Direto na escola - Escolas Sustentáveis, o recurso financeiro é para auxiliar as escolas no desenvolvimento de suas atividades voltadas às questões 


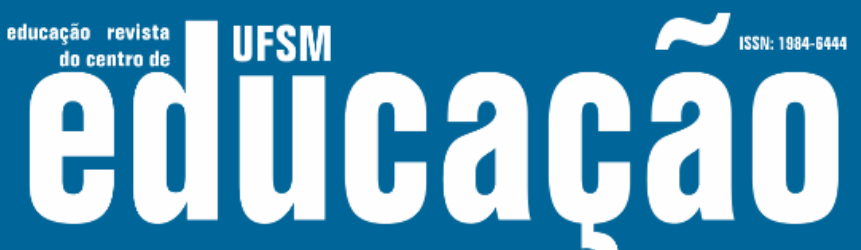

ISSN: 1984-6444 | http://dx.doi.org/10.5902/1984644439187

socioambientais cumprindo o estabelecido pelo programa. Um dos pré-requisitos para concorrer ao edital é a participação da escola na Comissão de Meio Ambiente e Qualidade de Vida (COM-VIDA). Esse impasse demostra a fragilidade no próprio sistema.

Sobre a implantação do plano de ação do PDDE-ES, 75\% dos gestores responderam que houve participação dos docentes na elaboração do plano, porém apenas $12,6 \%$ dos professores afirmaram que participaram da estruturação do plano (Tabela 1). Dentre os professores, $44,7 \%$ responderam não saber se a escola havia recebido o recurso do programa, e 42,7\% não responderam a essa questão o que também pode refletir o não conhecimento sobre a liberação do recurso ou da inserção da escola no programa. O desconhecimento por parte dos professores, dos projetos que a escola está participando demonstra falta de diálogo entre gestão e professores, uma vez que, é importante a comunicação efetiva e que todos saibam dos projetos desenvolvidos pela escola ou que esta participa.

No tocante ao conhecimento dos objetivos do PDDE-ES, 83,3\% dos gestores afirmaram que os professores tinham conhecimento dos mesmos, e que estes estavam propostos no plano de ação do projeto criado pela escola. Porém, quando questionado aos professores, $61,2 \%$ responderam não ter conhecimento dos objetivos do PDDE-ES, reforçando a falta de diálogo entre gestão e docentes pois, como a maioria dos gestores afirmou que os docentes participaram da construção do plano de ação, era esperado que estes tivessem conhecimento dos objetivos propostos. Essa ineficiência na comunicação dentro da escola acaba influenciando o andamento e execução de projetos de Educação Ambiental que não são tratados com a importância que requerem (Tabela 1). 


\section{Hism

ISSN: 1984-6444 | http://dx.doi.org/10.5902/1984644439187

Tabela 1 - Conhecimento e desenvolvimento do PDDE-ES nas escolas de Aracaju, inscritas em 2014.

\begin{tabular}{|c|c|c|c|c|}
\hline \multirow{2}{*}{$\begin{array}{l}\text { Programa Dinheiro Direto na Escola - } \\
\text { Escolas Sustentáveis (PDDE-ES) }\end{array}$} & \multicolumn{2}{|c|}{ Gestor } & \multicolumn{2}{|c|}{ Professor } \\
\hline & $\mathbf{n}$ & $\%$ & $\mathrm{n}$ & $\%$ \\
\hline \multicolumn{5}{|l|}{ Recebimento da verba do PDDE-ES } \\
\hline Sim & 2 & 16,7 & 13 & 12,6 \\
\hline Não & 10 & 83,3 & 46 & 44,7 \\
\hline Não respondeu & 0 & 0 & 44 & 42,7 \\
\hline \multicolumn{5}{|l|}{$\begin{array}{l}\text { Conhecimento dos objetivos do PDDE- } \\
\text { ES }\end{array}$} \\
\hline Sim & 10 & 83,4 & 26 & 23,3 \\
\hline Não & 2 & 16,6 & 63 & 61,2 \\
\hline Não respondeu & 0 & 0 & 16 & 15,5 \\
\hline \multicolumn{5}{|l|}{$\begin{array}{l}\text { Participação dos professores na } \\
\text { construção do plano de ação do PDDE- } \\
\text { ES }\end{array}$} \\
\hline Sim & 9 & 75 & & \\
\hline Não & 3 & 25 & & \\
\hline Total & 12 & 100 & 103 & 100 \\
\hline
\end{tabular}

Fonte: Elaboração própria dos autores (2017)

Dentro da proposta do PDDE-ES, o manual traz que deve ocorrer à efetiva participação dos professores na construção do plano de ação do programa (BRASIL, 2013), e que professores e gestores, assim como os demais membros da escola, tenham conhecimento e se envolvam no processo de construção do projeto, sendo este o melhor caminho para obter os resultados desejados (BRASIL, 2014).

O tempo que o professor leciona na escola também pode influenciar o seu conhecimento sobre os projetos. Ocorreram relatos de professores que justificaram o não conhecimento devido ao fato de não estarem na escola no ano de submissão da proposta. Contudo, vale ressaltar que a comunicação entre gestão e funcionários deve ocorrer de forma dinâmica e que um professor ao ingressar na escola pode também procurar se inteirar dos projetos que esta desenvolve e não somente esperar que essa informação venha da diretoria. A parceria entre gestão e docentes é primordial para um bom andamento das atividades da escola e para que estas alcancem resultados positivos, pois não é possível desenvolver um trabalho eficiente sem que todos façam parte desta construção, principalmente no ambiente escolar, onde ocorre o processo 


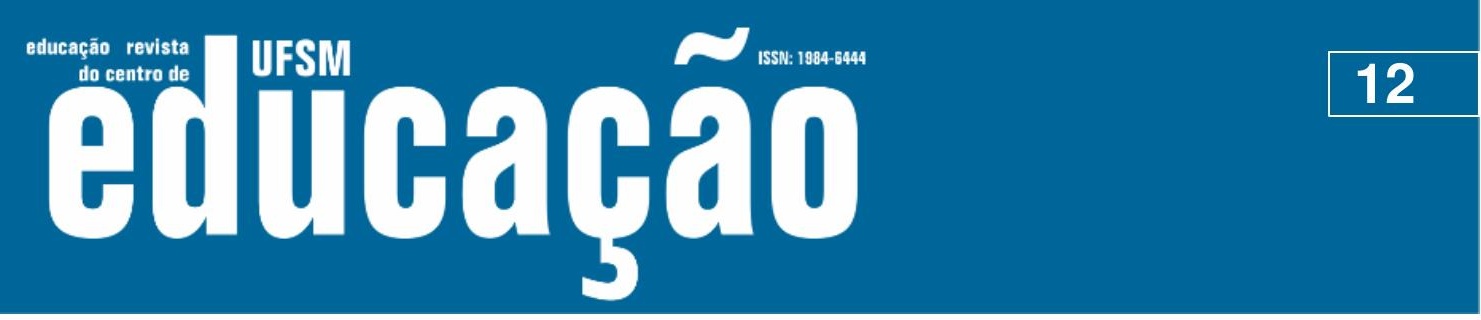

ISSN: 1984-6444 | http://dx.doi.org/10.5902/1984644439187

de troca de conhecimento e experiências, sendo o professor autor desta intermediação com seus alunos.

Mota (2016) ao analisar o conhecimento dos docentes no que se refere ao desenvolvimento do PDDE-ES em duas escolas de Santa Catarina, também identificou que os professores das escolas pesquisadas não tinham conhecimento quanto ao plano de ação desenvolvido pela escola e relataram que não fizeram parte desta construção, enquanto, o gestor de uma das escolas, afirmou que houve participação dos professores nesse momento, contradizendo as informações coletadas. É possível verificar que existem carências no momento da construção do plano de ação, tanto nas escolas pesquisadas por Mota (2016) quanto na presente pesquisa. Percebe-se que, a falta de diálogo entre a gestão e professores é um dos motivos para os projetos executados e/ou em execução não serem pautados com a devida importância, fragilizando a efetividade e o alcance de resultados positivos.

O conhecimento dos docentes quanto aos objetivos do Programa Dinheiro Direto na Escola-Escolas Sustentável não obteve diferença significativa quanto as variáveis sexo, faixa etária, nível de escolaridade dos professores, formação, série que leciona, disciplina que leciona e tempo de magistério. Vale ressaltar que o cruzamento não incluiu dados dos professores que não responderam as questões relativas ao tema (Tabela 2). Estes resultados corroboram com Silva et al., (2015) que relacionaram a idade com o conhecimento de professores aos temas ambientais e constataram que, a idade não interferiu no nível de conhecimento desses profissionais, demostrando que, o conhecimento acontece de maneira eventual e que a idade não impossibilita a busca por capacitação quanto aos temas abordados. Portanto, as idades dos docentes nestes dois estudos não são limitadores para a busca de novos conhecimentos voltados as questões ambientais, ou seja, a idade não é uma variável que impossibilita a formação continuada.Os fatores sócios demográficos e psicográficos não estiveram associados a diferenças no conhecimento desses professores quanto aos objetivos propostos nos planos de ações. A maioria dos professores $64(61,2 \%)$ afirma não conhecer tais objetivos (Tabela 2). Este é um resultado importante, pois professores e gestores são responsáveis pelos projetos em andamento e executados pela escola. 


\section{تulloapão}

ISSN: 1984-6444 | http://dx.doi.org/10.5902/1984644439187

Tabela 2 - Análise bivariada da variável do conhecimento sobre os objetivos do PDDEES de acordo com as variáveis sociodemográficas e profisiográficas dos professores das escolas inscritas no PDDE-ES, 2014.

\begin{tabular}{|c|c|c|c|c|c|}
\hline \multicolumn{2}{|c|}{ Variáveis } & \multicolumn{4}{|c|}{ Conhecimento dos objetivos do PDDE-ES } \\
\hline & & Sim & Não & Total & $\boldsymbol{P}$ \\
\hline \multirow{2}{*}{ Sexo } & Masculino & 6 & 13 & 19 & \\
\hline & Feminino & 18 & 50 & 68 & \\
\hline Total & & 24 & 63 & 87 & 0,66 \\
\hline \multirow{4}{*}{$\begin{array}{c}\text { Nível de } \\
\text { Escolaridade }\end{array}$} & Superior & 10 & 15 & 25 & \\
\hline & Especialização & 13 & 47 & 60 & \\
\hline & Mestrado & 0 & 1 & 1 & \\
\hline & $\begin{array}{l}\text { Mestrado em } \\
\text { andamento }\end{array}$ & 1 & 0 & 1 & \\
\hline Total & & 24 & 63 & 87 & 0,112 \\
\hline \multirow{3}{*}{ Formação } & Pedagogia & 12 & 30 & 42 & \\
\hline & Outras formações & 8 & 27 & 35 & \\
\hline & Não respondeu & 4 & 6 & 10 & \\
\hline Total & & 24 & 63 & 87 & 0,553 \\
\hline \multirow{3}{*}{ Série que leciona } & Do $1^{\circ}$ ao $5^{\circ}$ Ano & 18 & 44 & 62 & \\
\hline & Do 6ํa ao 9 Ano & 6 & 18 & 24 & \\
\hline & Não respondeu & & 1 & 1 & \\
\hline Total & & 24 & 63 & 87 & 0,769 \\
\hline \multirow{2}{*}{$\begin{array}{c}\text { Disciplina que } \\
\text { leciona }\end{array}$} & Polivalente & 15 & 36 & 51 & \\
\hline & Não polivalente & 8 & 26 & 34 & \\
\hline Total & & 23 & 62 & 85 & 0,55 \\
\hline \multirow{2}{*}{$\begin{array}{l}\text { Tempo de } \\
\text { magistério }\end{array}$} & $\begin{array}{l}\text { Até } 12 \text { anos de } \\
\text { magistério }\end{array}$ & 12 & 29 & 41 & \\
\hline & $\begin{array}{l}\text { Mais de } 12 \text { anos de } \\
\text { magistério } \\
\end{array}$ & 11 & 29 & 40 & \\
\hline \multirow[b]{3}{*}{ Faixa etária } & & 23 & 58 & 81 & 0,86 \\
\hline & De 26 a 39 anos & 11 & 28 & 39 & \\
\hline & De 40 a 55 anos & 10 & 31 & 41 & \\
\hline Total & & 21 & 59 & 80 & 0,698 \\
\hline
\end{tabular}

Fonte: Elaboração própria dos autores (2017).

\section{Dificuldades na execução de atividades e projetos de Educação Ambiental}

Em relação às dificuldades encontradas para execução das práticas de Educação Ambiental e sustentabilidade, gestores de 10 escolas, incluindo aquelas que receberam ou não o recurso, afirmaram ter encontrado dificuldades e problemas 


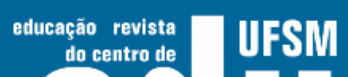

ISSN: 1984-6444 | http://dx.doi.org/10.5902/1984644439187

na condução dessas atividades. Somente um dos 12 gestores participantes afirmou não ter dificuldades para a realização das atividades de educação ambiental e práticas sustentáveis, e outro não respondeu a essa questão (Tabela 3).

Tabela 3 - Dificuldades de gestores e professores na execução de atividades e projetos de Educação Ambiental nas escolas de Aracaju, inscritas em 2014 no PDDEES.

\begin{tabular}{|c|c|c|c|c|}
\hline \multirow{2}{*}{$\begin{array}{l}\text { Dificuldades ou problemas na } \\
\text { execução de práticas de EA e } \\
\text { sustentabilidade }\end{array}$} & \multicolumn{2}{|c|}{ Gestor } & \multicolumn{2}{|c|}{ Professor } \\
\hline & $\mathbf{n}$ & $\%$ & $\mathbf{n}$ & $\%$ \\
\hline Sim & 2 & 16,7 & 4 & 3,9 \\
\hline Não & 0 & 0 & 7 & 6,1 \\
\hline \multicolumn{5}{|c|}{$\begin{array}{l}\text { Dificuldades para realização de } \\
\text { projetos de Educação Ambiental na } \\
\text { sua escola }\end{array}$} \\
\hline Sim & 9 & 75 & 43 & 41,7 \\
\hline Não & 3 & 25 & 44 & 42,8 \\
\hline Não respondeu & 0 & 0 & 16 & 15,5 \\
\hline \multicolumn{5}{|c|}{$\begin{array}{l}\text { Desenvolvimento de atividades de Educação Ambiental } \\
\text { sem o recurso do PDDE-ES }\end{array}$} \\
\hline Sim & 6 & 50,0 & 29 & 28,2 \\
\hline Não & 3 & 25,0 & 8 & 7,8 \\
\hline Não respondeu & 1 & 8,3 & 9 & 8,7 \\
\hline \multicolumn{5}{|c|}{$\begin{array}{l}\text { Dificuldades ou problemas na execução de } \\
\text { práticas de Educação Ambiental } \\
\end{array}$} \\
\hline Sim & 8 & 75,0 & 23 & 22,3 \\
\hline Não & 1 & 8,3 & 11 & 10,7 \\
\hline Não respondeu & 1 & 8,3 & 12 & 11,7 \\
\hline Total & 12 & 100 & 103 & 100 \\
\hline
\end{tabular}

a - Responderam a essa questão somente as escolas que receberam o recurso

b - Responderam a essa questão somente as escolas que não receberam o recurso

Fonte: Elaboração própria dos autores (2017).

O gestor de uma das escolas que recebeu o recurso também apontou dificuldade em relação ao plano de ação, alegando que o planejamento construído na antiga gestão não contemplava as principais necessidades da escola, o que impossibilitou a resolução das principais pendências, visto que, não é autorizado 


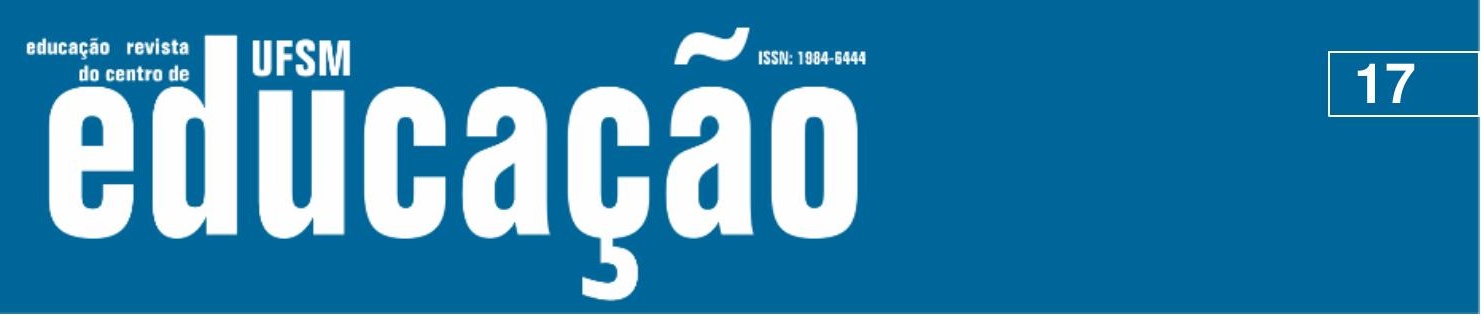

ISSN: 1984-6444 | http://dx.doi.org/10.5902/1984644439187

Ambiental que difunde que a educação ambiental deve ser executada de forma transversal, integrada e contínua, em todas as formas de ensino (BRASIL, 1999). O relato deste gestor demonstra que a Política Nacional de Educação Ambiental não é trabalhada no ambiente escolar de maneira fidedigna, perpassando por todas as disciplinas, como de fato é requerida, e sim de forma pontual e superficial.

Bizerril e Faria (2001) trabalhando no Distrito Federal com professores de escolas particulares e públicas que lecionavam no ensino fundamental, observaram que os temas ambientais geralmente eram abordados pelos professores de ciências e geografia. Em escolas no município de Anta Gorda, RS, Cittolin e Putzke (2002) também constataram que os temas relacionados ao meio ambiente eram tratados na maioria pelos professores de ciências. Esses resultados confirmam que os temas ambientais são de fato transferidos, para os professores de ciências, que são culturalmente responsabilizados por desenvolver esse tipo de atividade no ambiente escolar, sendo urgente a necessidade de mudança nessa cultura para que a EA se torne efetiva dentro da escola.

Nardy e Estevão, (2015) realizaram uma pesquisa em uma escola particular no estado do Paraná, com alunos do ensino fundamental e observaram que, as atividades de Educação Ambiental trabalhadas na escola foram bem aceitas e executadas pelos alunos, e o envolvimento destes foi efetivo, tendo como resultado a sensibilização sobre suas responsabilidades e sobre a relevância das questões ambientais. Ainda no trabalho, os autores discutem sobre a não aceitação de uma das metodologias propostas para a execução do projeto, e neste caso, a solução encontrada foi alterar a metodologia, mostrando que a adequação do método à realidade do público alvo é um passo importante para o sucesso de projeto de Educação Ambiental. Neste contexto, os autores mostram que é possível trabalhar com os discentes a Educação Ambiental e obter resultados satisfatórias.

Os resultados de outros trabalhos mostram o quanto é notório utilizar metodologias adequadas e que contemplem a realidade do local e público participante e que nestes casos, é nítido o maior interesse e comprometimento com a participação nos projetos propostos. Neste sentido e para que isso realmente aconteça, é 


\section{تilfoarẫ}

ISSN: 1984-6444 | http://dx.doi.org/10.5902/1984644439187

necessário o envolvimento de professores e gestores e que estes discutam e articulem uma melhor forma para trabalhar as questões ambientais no ambiente escolar.

Nas escolas participantes que não receberam o recurso $28,2 \%$ dos professores relataram já ter realizado alguma atividade de educação ambiental, mas que estas geralmente ocorrem de forma pontual. Conforme afirmam as diretrizes dos PCNs (BRASIL,1998), a Educação Ambiental deve ser tratada como tema transversal, onde as questões socioambientais devem ser trabalhadas na comunidade escolar, de forma articulada e contínua, garantindo que todos tenham acesso ao conhecimento.

Deste modo, percebe-se que um conjunto de variáveis podem estar comprometendo a execução das práticas de sustentabilidade e projetos de Educação Ambiental no ambiente escolar o que reforça a necessidade de reflexão e discussão sobre essas fragilidades e como professores e gestores podem mudar esse cenário contribuindo para um maior envolvimento de toda a comunidade escolar.

Os cursos de capacitação continuada são um ponto importante para a formação do profissional na inserção e articulação da Educação Ambiental e sustentabilidade no ambiente escolar. Feitosa et al. (2016) relata que a falta de capacitação dos professores para tratar a educação ambiental na escola é uma barreira, onde apesar dos docentes conhecerem os temas que devem ser desenvolvidos, não se sentem preparados para inseri-los no seu planejamento.

No presente trabalho, foram realizadas atividades educativas de cunho sustentável e observou-se uma boa aceitação por parte dos alunos que participaram efetivamente, mostrando interesse por todos os temas propostos e contradizendo a fala de professores e gestores quanto à falta de interesse destes alunos.

No cruzamento das variáveis com as dificuldades e problemas na execução de práticas de Educação Ambiental somente a variável "série que leciona" foi significativa (Tabela 4). 


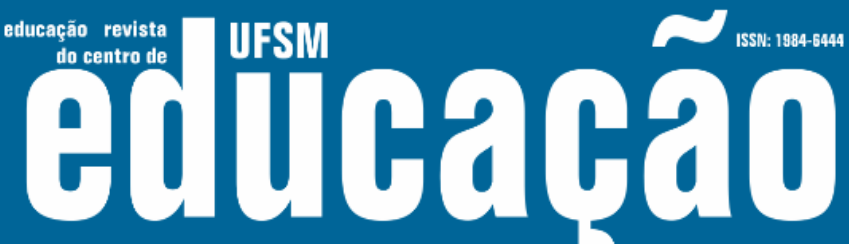

ISSN: 1984-6444 | http://dx.doi.org/10.5902/1984644439187

Tabela 4 - Análise bivariada dificuldades e problemas na execução de práticas de Educação Ambiental de acordo com as variáveis sociodemográficas e profisiográficas dos professores das escolas inscritas no PDDE-ES, 2014.

\begin{tabular}{|c|c|c|c|c|c|}
\hline \multirow[t]{4}{*}{ Variáveis } & \multicolumn{5}{|c|}{ Dificuldades e problemas na execução de práticas de EA } \\
\hline & \multirow{3}{*}{$\begin{array}{l}\text { Masculino } \\
\text { Feminino }\end{array}$} & \multirow{3}{*}{$\begin{array}{c}\text { Sim } \\
7 \\
16 \\
\end{array}$} & \multirow{3}{*}{$\begin{array}{c}\text { Não } \\
4 \\
7 \\
\end{array}$} & \multirow{3}{*}{\begin{tabular}{c|} 
Total \\
11 \\
23 \\
\end{tabular}} & \multirow[t]{3}{*}{$p$} \\
\hline & & & & & \\
\hline & & & & & \\
\hline Total & & 23 & 11 & 34 & 0,73 \\
\hline \multirow{4}{*}{ Nível de Escolaridade } & Superior & 7 & 3 & 10 & \\
\hline & Especialização & 14 & 8 & 22 & \\
\hline & Mestrado & 1 & 0 & 1 & \\
\hline & Mestrado curso & 1 & 0 & 1 & \\
\hline Total & & 23 & 11 & 34 & 0,767 \\
\hline \multirow{3}{*}{ Formação } & Pedagogia & 9 & 8 & 17 & \\
\hline & Outras formações & 12 & 2 & 14 & \\
\hline & Não respondeu & 2 & 1 & 3 & \\
\hline Total & & 23 & 11 & 34 & 0,152 \\
\hline \multirow{2}{*}{ Série que leciona } & Do $1^{\circ}$ ao $5^{\circ}$ Ano & 15 & 11 & 26 & \\
\hline & Do $6^{\circ}$ ao $9^{\circ}$ Ano & 8 & 0 & 8 & \\
\hline Total & & 23 & 11 & 34 & $0,025^{\star}$ \\
\hline \multirow{2}{*}{ Disciplina que leciona } & Polivalente & 11 & 8 & 19 & \\
\hline & Não polivalente & 12 & 3 & 15 & \\
\hline Total & & 23 & 11 & 34 & 0,171 \\
\hline Tempo de magistério & $\begin{array}{l}\text { Até } 12 \text { anos de } \\
\text { magistério } \\
\text { Mais de } 12 \text { anos de } \\
\text { magistério }\end{array}$ & $\begin{array}{c}6 \\
15 \\
\end{array}$ & $\begin{array}{l}6 \\
5\end{array}$ & $\begin{array}{l}12 \\
20\end{array}$ & \\
\hline Total & & 21 & 11 & 32 & 0,149 \\
\hline \multirow[t]{2}{*}{ Faixa etária } & De 26 a 39 anos & 6 & 7 & 13 & \\
\hline & De 40 a 55 anos & 13 & 4 & 17 & \\
\hline Total & & 19 & 11 & 30 & 0,88 \\
\hline
\end{tabular}

Fonte: Elaboração própria dos autores (2017).

Esse resultado aponta que a série está relacionada com as dificuldades encontradas, o que reforça a necessidade de planejamento dessas atividades para abordar os temas, com metodologias adequadas para a idade das crianças. Foram nas séries iniciais que os professores encontram maiores dificuldades, sendo 


\section{N-Tis

ISSN: 1984-6444 | http://dx.doi.org/10.5902/1984644439187

necessário pontuar que, é a partir do ensino base que as temáticas ambientais e sustentáveis devem ser inseridas, pois o indivíduo está no início da formação e construção do conhecimento. Ademais todos os professores do $6^{\circ}$ ao $9^{\circ}$ ano que responderam a essa questão relataram dificuldades ou problemas na execução de práticas de Educação Ambiental o que implica na necessidade de capacitação também para os professores destas séries.

Os professores participantes da pesquisa de Araújo e Oliveira (2008), que lecionavam em escolas públicas e privadas do ensino médio, em Recife, Pernambuco, alegaram que no percurso da sua formação os temas ambientais foram abordados esporadicamente elou em nenhum momento do curso. Neste sentido, percebe-se que, a dificuldade em inserir em seus conteúdos as temáticas ambientais é um reflexo da formação do sujeito, uma vez que, essas questões não são trabalhadas na formação inicial, dificultando a articulação e inserção da Educação Ambiental no planejamento escolar e mostrando a fragilidade com a qual os temas ambientais são abordados.

\section{Interferência do PDDE-ES na comunidade}

Com relação às duas escolas que receberam o recurso, um dos gestores disse acreditar que o PDDE-ES interfere na comunidade local, e o outro não acredita nessa interferência. Quando consideradas todas as escolas, que receberam e ou não o recurso, 34,9\% dos professores concorda que o PDDE-ES interfere na comunidade local e como pontos positivos foram citados que o programa pode gerar melhorias no relacionamento entre comunidade e escola, integração dos alunos, contribuição para uma boa relação entre alunos e escola (Tabela 5). 


\section{- Tusm

ISSN: 1984-6444 | http://dx.doi.org/10.5902/1984644439187

Tabela 5 - Interferência do PEDDE-ES na comunidade onde a escola está inserida.

\begin{tabular}{lcc|cc}
\hline $\begin{array}{l}\text { Interferência do PDDE-ES na } \\
\text { comunidade local }^{\mathbf{a}}\end{array}$ & Gestor & \multicolumn{2}{c}{ Professor } \\
\hline & $\mathbf{n}$ & $\%$ & $\mathbf{n}$ & $\%$ \\
\hline Sim & 1 & 8,3 & 10 & 9,7 \\
Não & 1 & 8,3 & 1 & 1 \\
Não respondeu & 0 & 0 & 2 & 1,9 \\
\hline Interferência do PDDE-ES na comunidade local $^{\mathbf{b}}$ & & & & \\
\hline Sim & 5 & 41,7 & 26 & 25,2 \\
Não & 5 & 41,7 & 9 & 8,7 \\
Não respondeu & 0 & 0 & 11 & 10,7 \\
\hline Total & $\mathbf{1 2}$ & $\mathbf{1 0 0}$ & $\mathbf{1 0 3}$ & $\mathbf{1 0 0}$ \\
\hline
\end{tabular}

a - Responderam a essa questão, somente as escolas que receberam o recurso

b - Responderam a essa questão, somente as

escolas que não receberam o recurso

Fonte: Elaboração própria dos autores (2017)

\section{Projeto Político Pedagógico}

$\mathrm{Na}$ análise do Projeto Político-Pedagógico (PPP), constatou-se que apenas quatro de dez escolas abordavam a inserção da temática Educação Ambiental e Sustentabilidade no conteúdo no seu PPP. Esse resultado reforça que os temas ambientais ainda não fazem parte efetiva dos Projetos Político-Pedagógicos, fragilizando o processo de ensino-aprendizagem, uma vez que a ausência de abordagem dessas temáticas não fornece suporte para sua aplicação que fica restrita a atividades pontuais, como observado por diversos outros autores (ARAGÃO et al, 2011; FERRARI, ZACUL; 2016). Vale ressaltar, que um dos objetivos da COM-VIDA, é a inserção das questões ambientais e de sustentabilidade no PPP, deste modo, às escolas que estão inscritas no Programa Dinheiro Direto na Escola - Escolas Sustentáveis não estão conseguindo colocar em prática a proposta requerida pelo programa.

Quanto à interdisciplinaridade da Educação Ambiental nos PPPs, nove escolas não abordavam o tema de forma interdisciplinar, em seus conteúdos e sete escolas 


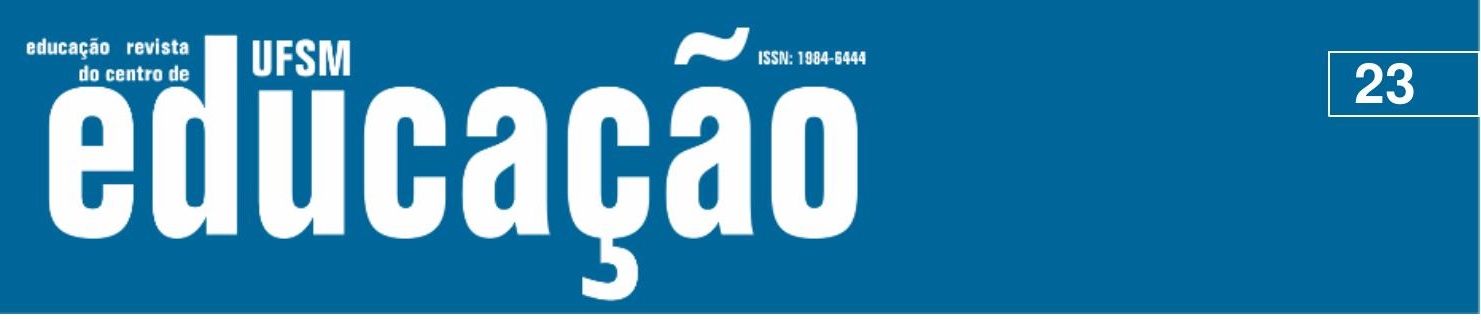

ISSN: 1984-6444 | http://dx.doi.org/10.5902/1984644439187

ineficiência no diálogo entre gestão e professores são entraves que parecem ter comprometido a efetividade dessas atividades no ambiente escolar. Foi possível verificar que professores não tinham conhecimento do programa, e não participaram da construção do plano de ação, prejudicando o alcance dos objetivos propostos no plano.

Foi constatada a existência de atividades de Educação Ambiental, porém, estas ainda são realizadas de forma pontual, não contemplando projetos continuados e transversais. As fragilidades quanto ao conhecimento e aplicabilidade da Educação ambiental por professores e gestores foi evidente, reforçando a necessidade de capacitação e formação continuada para que esses profissionais possam atuar de forma mais efetiva.

O Programa Dinheiro Direto na Escola-Escolas Sustentáveis é de suma importância para que as escolas possam continuar trabalhando as questões socioambientais na escola. O incentivo financeiro e a proposta do PDDE-ES estimulam a comunidade escolar na busca por alternativas e metodologias para transformar o ambiente em um espaço que eduque para a sustentabilidade. Porém, é necessário que os recursos financeiros cheguem até as escolas, para que as mesmas possam desenvolver as atividades propostas em seus planos de ações, concretizando os objetivos propostos no programa.

Outro ponto também observado foi à falta dos temas ambientais nos Projetos Políticos Pedagógicos das Escolas, tradados eventualmente, não contemplando todas as disciplinas de forma transversal. É importante que esses temas sejam inseridos e façam parte dos Projetos Políticos Pedagógicos para que a sensibilização seja efetiva com todos aprendendo sobre a importância dos cuidados com o meio ambiente e utilizando esse aprendizado no cotidiano escolar e na rotina da comunidade por meio da mudança de hábitos e ações em busca pela conservação ambiental local.

O Programa Dinheiro Direto na Escola - Escolas Sustentáveis apresenta um leque de possibilidades para o início das mudanças no espaço escolar e o alcance de novos olhares e discussões sobre a crise socioambiental que o planeta enfrenta. Porém, foi percebido nesta pesquisa que o PDDE-ES ainda não foi efetivamente adotado pelas escolas e que as questões ambientais ainda são tratadas de forma 


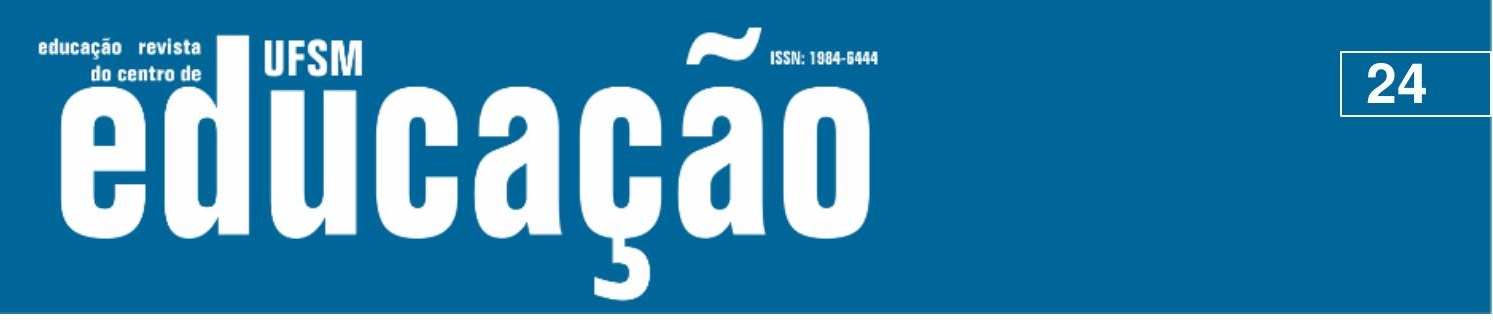

ISSN: 1984-6444 | http://dx.doi.org/10.5902/1984644439187

superficial e aleatória. No entanto, esta pesquisa mostra as fragilidades e dificuldades enfrentadas pelas escolas na execução do PDDE-ES, e pode contribuir para que gestores e professores revejam onde necessitam intervir para que o programa funcione e alcance as metas necessárias para criação de um espaço realmente sustentável que desenvolva de forma permanente as ações propostas e proporcione melhor qualidade de vida para a comunidade escolar.

\section{Referências}

ARAGÃO, João Paulo Gomes de Vasconcelos; SANTOS, Karolina Maria Bezerra; SILVA Marlene Maria. Gestão Ambiental e Escola: A Construção de uma Atitude Ambiental. Revista Ambiente e Educação, n. 2, p. 27-40, 2011.

ARAÚJO, Monica Lopes Folena; OLIVEIRA, Maria Marly. Formação de professores de biologia e educação ambiental: Contribuições, deficiências e estratégias. Revista Eletrônica Mestrado Educação Ambiente, Rio Grande do Sul, p. 256-273, 2008.

BARBO, Ivaldete de Paula Pereira. O despertar da consciência ambiental: um diagnóstico das práticas de educação ambiental formal no ensino público de Anápolis, Goiás. 2009. 161 f. Dissertação. (Mestrado em Sociedade, Tecnologia e Meio Ambiente) - Programa de Pós-Graduação Stricto Sensu - Mestrado Multidisciplinar em Sociedade, Tecnologia e Meio Ambiente, Anápolis, 2009.

BIANCHINI, Débora Cristina et al. Sustentabilidade e Educação Ambiental na Escola Estadual de Ensino Fundamental Waldemar Sampaio Barros.Revista Monografias Ambientais, Santa Maria, p.188-194, 2015.

BIONDO, Evandro. A Educação Ambiental na Escola Básica do Vale do Itaquari/RS - Atuação Temas e Dificuldades dos Docentes. 2008. $131 \mathrm{f}$. Dissertação (Mestrado em Ambiente e Desenvolvimento) - Programa de PósGraduação Strictu Sensu, Lajeado, 2008.

BIZERRIL; Marcelo Ximenes Aguiar; FARIA, Dóris Santos de. Percepção de professores sobre a educação ambiental no ensino fundamental. Revista Brasileira de Estudos Pedagógicos, Brasília, n. 200/201/202, p. 57-69, jan-dez. 2001.

BOSA, Cláudia Regina, TESSER, Halandey Camilo de Borba. Desafios da Educação Ambiental nas Escolas Municipais do Município de Caçador - SC. Revista Monografias Ambientais, Santa Maria, n. 2, p. 2996-3010, mar. 2014.

BRASIL. Ministério da Educação. Programa Dinheiro Direto na Escola - PDDE. Escolas Sustentáveis. Guia de Orientações Operacionais. Brasília, DF, 2014. 


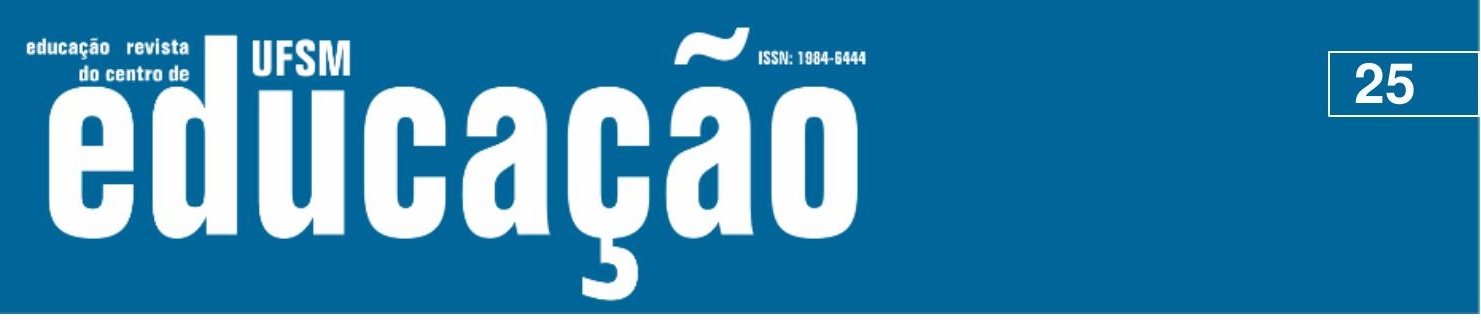

ISSN: 1984-6444 | http://dx.doi.org/10.5902/1984644439187

BRASIL. Ministério da Educação. Secretaria de Educação Continuada, Alfabetização e Diversidade. Formando Com-Vida Comissão do Meio Ambiente e Qualidade de Vida na Escola : Construindo Agenda 21 na Escola. Brasília: MEC, DF, 2004.

BRASIL. Ministério da Educação. Secretaria de Educação Continuada, Alfabetização e Diversidade. Brasília: SECAD/MEC), DF, 2007.

BRASIL. Ministério da Educação. Educação na diversidade: O que Fazem as Escolas que Dizem que Fazem Educação Ambiental. Organização: Rachel Trajber, Patrícia Ramos Mendonça. Secretaria de Educação Continuada, Alfabetização e Diversidade. Brasília, DF, 2007.

BRASIL. Ministério da Educação. Secretaria de Educação Continuada, Alfabetização, Diversidade. Formando Com-Vida, Comissão do meio Ambiente e Qualidade de Vida na Escola: Construindo a Agenda 21 na Escola. Ministério do Meio Ambiente. Brasília, DF, 2007.

BRASIL. Ministério da Educação. Secretaria de Educação Continuada, Alfabetização, Diversidade e Inclusão. Manual Escolas Sustentáveis. Brasília: SECADI/MEC, DF, 2013.

BRASIL. Presidência da República. Política Nacional de Educação Ambiental. Brasília, DF, 1999.

BRASIL. Secretaria de Educação Fundamental. Parâmetros Curriculares Nacionais: terceiro e quarto ciclos: apresentação dos temas transversais/ Secretaria de Educação Fundamental. Brasília: MEC/SEF, DF, 1998.

BRASIL.Ministério da Educação. Secretaria de Educação Continuada, Alfabetização, Diversidade e Inclusão. Vamos Cuidar do Brasil com Escolas Sustentáveis. Brasília: Saic, DF, 2012.

CARNEIRO, Benedita Simone; OLIVEIRA, Maria Auxiliadora Silva; MOREIRA, Raulzito Fernandes. Educação ambiental na escola pública. Revista Brasileira de Educação Ambiental, São Paulo, n. 1, p. 25-36, 2016.

CITTOLIN, César; PUTZKE, Jair. A educação ambiental em escolas do município de Anta Gorda - RS, BRASIL. Caderno de Pesquisa Série Biologia, Santa Cruz do Sul, n. 2, p. 39-52, jul-dez. 2002

DOURADO, Juscelino; BELIZARIO, Fernanda; PAULINO, Alciana. Escolas Sustentáveis. 1 ed. São Paulo: Oficina de textos, 2015.

FEITOSA, Anny Kariny; SILVA, Cláudia Maria; SILVA, Jorge Luiz. Educação Ambiental na percepção de professores em uma escola de ensino fundamental no Município de Iguatu, CE. Revista Educação Ambiental em Ação, n. 56, p. 1-6, junago. 2016. 


\section{uss \\ 15SN: 1984-6444

ISSN: 1984-6444 | http://dx.doi.org/10.5902/1984644439187

SILVA, Lílian Ferreira Gomes. Implantação de espaços educadores sustentáveis: estudo de caso em escola pública do município de Poços de Caldas, MG. 2014. 116 f. Dissertação. (Mestrando em Ciência e Engenharia Ambiental) - Programa de Pós-Graduação em Ciência e Engenharia Ambiental Universidade Federal de Alfena, Poços de Caldas, 2014.

SILVA, Lilian Ferreira Gomes; SILVEIRA, Alexandre. Implantação de Espaços Educadores Sustentáveis: Estudo de Caso em Escola Pública. Revista Monografias Ambientais, Santa Maria, n. 1, p. 288-301, jan-abr. 2016.

TAVAREZ, Gessica, et al. Oficinas de Reciclagem em Salas de Aula: Uma Importante Ferramenta de Educação Ambiental. In: III CONGRESSO NACIONAL DE EDUCAÇÃO AMBIENTAL \& V ENCONTRO NORDESTINO DE BIOGEOGRAFIA, 2013, João Pessoa. Anais do III Encontro Nacional de Educação Ambiental e V Encontro Nordestino de Biogeografia. Resíduos, Saneamento ambiental e reciclagem. João Pessoa, 2013. Disponível em: http://www.cnea.com.br/wpcontent/uploads/2013/03/III-CNEA-e-V-ENBio-VOL-2-final22.01.20141.pdf. Acesso em 16 jul. 2013.

TRAJBER, Rachel; SATO, Michèle. Escolas Sustentáveis: Incubadoras de Transformações nas Comunidades. Revista Eletrônica do Mestrado em Educação Ambiental, RS, p. 71-78, set. 2010.

\section{Correspondência}

Maraisa de Oliveira Silva - Universidade Tiradentes - R. Lagarto, 236 - Centro, Aracaju, Sergipe, Brasil.

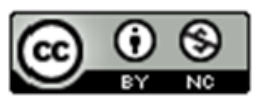

This work is licensed under a Creative Commons Attribution-NonCommercial 4.0 International (CC BY-NC 4.0) 